\title{
A concepção de deficiência em discussáo: ponto de vista de docentes de Terapia Ocupacional ${ }^{1}$
}

\author{
Luciana Ramos Baleotti ${ }^{a}$, Sadao Omote ${ }^{b}$ \\ ${ }^{a}$ Departamento de Fisioterapia e Terapia Ocupacional, \\ Faculdade de Filosofia e Ciências, Universidade Estadual Paulista - UNESP, Marília, SP, Brasil \\ ${ }^{\text {b} D e p a r t a m e n t o ~ d e ~ E d u c a c ̧ a ̃ o ~ E s p e c i a l, ~ P r o g r a m a ~ d e ~ P o ́ s-G r a d u a c ̧ a ̃ o ~ e m ~ E d u c a c ̧ a ̃ o, ~ F a c u l d a d e ~ d e ~ F i l o s o f i a ~ e ~}$ \\ Ciências, Universidade Estadual Paulista - UNESP, Marília, SP, Brasil
}

\begin{abstract}
Resumo: A forma como concebemos as pessoas com deficiência parece influenciar as ações destinadas a elas. Terapeutas ocupacionais representam uma parcela de profissionais da área da saúde que direcionam suas ações pautados em uma visão abrangente do que representa a deficiência. Objetivou-se identificar e analisar a concepção de deficiência na perspectiva de docentes com formação em Terapia Ocupacional. Participaram deste estudo 15 docentes, sendo sete de duas universidades públicas e oito de duas universidades privadas, localizadas em cidades de médio porte do estado de São Paulo. A coleta de dados foi realizada por meio de um instrumento denominado Escala de Avaliação da Concepção de Deficiência. Os resultados apontam que o grupo estudado apresenta maior tendência às concepções interacionista e social de deficiência. O estudo traz contribuições para a compreensão da concepção que os docentes de cursos de Terapia Ocupacional têm acerca da deficiência, o que certamente conduz o fazer pedagógico deles, afetando a formação de futuros profissionais.
\end{abstract}

Palavras-chave: Terapia Ocupacional, Concepção de Deficiência, Ensino.

\section{The conception of disability under discussion: the point of view of Occupational Therapy professors}

\begin{abstract}
The way one conceives disabled people seems to influence the actions directed toward them. Occupational therapists constitute a part of health professionals that direct their actions based on a comprehensive view of disability. The aim of this study was to identify and analyze the conception of disability from the standpoint of occupational therapists. Fifteen university teachers of Occupational Therapy undergraduate courses participated in this study: seven from public universities and eight from private institutions, located in mid-sized municipalities in the state of São Paulo. The data were collected by means of a scale denominated "Escala de Avaliação da Concepção de Deficiência" (Rating Scale for Conception of Disability). The results show that the subjects tend to follow interactional, social conceptions of disability. This study yields contributions to understand the conception of disability held by teachers of Occupational Therapy. This conception certainly guides their teaching performance and affects the training of future professionals.
\end{abstract}

Keywords: Occupational Therapy, Conception of Disability, Education.

\footnotetext{
Autor para correspondência: Luciana Ramos Baleotti, Faculdade de Filosofia e Ciências, Universidade Estadual Paulista, Campus de Marília, Av. Hygino Muzzi Filho, 737, Mirante, CEP 17525-000, Marília, SP, Brasil, e-mail: baleotti@ marilia.unesp.br 


\section{Introdução}

As práticas sociais destinadas às pessoas com deficiência vêm se modificando de acordo com o conceito de homem e o de deficiência que constituem o pensamento de cada época. $\mathrm{Na}$ antiguidade, as pessoas consideradas deficientes eram praticamente exterminadas por meio do abandono. Já na Idade Média o advento do cristianismo influenciou a difusão do pensamento cristão e o entendimento de que todas as pessoas eram possuidoras de alma e manifestaçáo de Deus. Em função disso, as pessoas com deficiência não podiam mais ser abandonadas, pois também adquiriram um status humano e, portanto, eram retentoras de uma alma. Sob a forte influência do cristianismo, a deficiência era concebida de duas formas opostas: ora como possessão do demônio ora como desígnio divino. Concebida a deficiência de uma maneira ou de outra, as atitudes da sociedade frente às pessoas com deficiência eram representadas por intransigência e punição, essa caracterizada por açóes de aprisionamento, tortura, açoites e outras penalidades severas (BRASIL, 2000).

A partir do século XVI, o avanço da medicina influenciou a construção de uma concepção organicista da deficiência e essa passou a configurar-se como um problema de ordem médica e não mais religioso. Nos séculos subsequentes fortaleceu-se a visão organicista da deficiência; o corpo e a pessoa com deficiência tornaram-se objetos de investigação da ciência médica. E é nessa perspectiva que começam a se estruturar as definiçóes científicas de deficiência (BALEOTTI; DEL-MASSO, 2008).

[...] a incorporação da natureza humana pela análise científica foi feita a partir dos progressos da biologia (século XIX), que carregou todo o reducionismo e o determinismo biológico. [...] Estabeleceram-se, assim, normas gerais para as propriedades, sendo qualquer desvio da norma interpretado como anomalia, que poderia refletir problemas médicos, dos quais o indivíduo deveria ser tratado. (PAN, 2008, p. 40-41).

A concepção organicista e/ou médica considera a deficiência como algo que está presente no indivíduo identificado como deficiente, no seu organismo ou comportamento, e ausente nas pessoas consideradas não deficientes. Tal compreensão implica a maneira de se lidar com as deficiências e com as pessoas com deficiência. A concepção médica de deficiência faz com que as açóes sejam centradas exclusivamente na pessoa que se supóe seja portadora dessa condição.
A tendência é localizar no indivíduo a deficiência e, muitas vezes, também a sua causa (OMOTE, 1994).

A concepção médica esteve presente por décadas, passando de geração para geração, com base em conceitos hoje considerados ultrapassados acerca da pessoa com deficiência e da deficiência (BALEOTTI; DEL-MASSO, 2008).

No entanto, atualmente, em diversos âmbitos da área da saúde e da educação, ainda é mantida a concepçáo de deficiência como condição puramente biológica, que define a deficiência como o resultado de características ou elementos patogênicos presentes no organismo do indivíduo (VIEIRA; DENARI, 2008).

No estudo de Mori e Oliveira (2012), todos os participantes entenderam a deficiência como uma condição médica, remetendo a uma concepção que agrega à pessoa com deficiência um caráter organicista e assistencial. Entre os profissionais que atuam em serviços de saúde, a abordagem assumida parece ser centrada na pessoa com deficiência. Investigando a representação que membros de uma equipe de serviço público de saúde tinham acerca da deficiência, Othero e Dalmaso (2009) concluíram que o foco de atenção recaía sobre o corpo, os cuidadores e as condiçôes de moradia das pessoas com deficiência. Questóes relativas a direitos e participaçáo social foram menos destacadas pelos participantes da pesquisa.

Além da concepção médica de deficiência, Telford e Sawrey (1988) descreveram outros dois conceitos: o embasado em determinantes sociais e o interacionista. No primeiro, a deficiência é interpretada como decorrente de fatores sociais, emocionais ou educacionais, os quais podem estar prejudicando ou causando dificuldades para o indivíduo. Trata-se de uma concepção centrada na situaçáo, na qual é no ambiente que se encontram as principais causas do desvio incapacitador. Embora os fatores ou as explicaçóes para as dificuldades dos indivíduos sejam externos, o foco ainda recai sobre o próprio indivíduo, pois é ele que tem dificuldades.

Tendo como foco o indivíduo e o meio, os autores descreveram o modelo interacionista de deficiência, no qual a deficiência é interpretada com base na complexa interação entre o indivíduo e o meio social. Mais recentemente, Resende e Neri (2005, p. 124) apontaram que

A deficiência pode ser socialmente definida como o produto do descompasso entre as condições do indivíduo afetado por uma limitação funcional, as suas expectativas quanto à execução das atividades básicas e instrumentais de vida diária, as demandas ambientais nessa 
direção e a escassez ou a inadequação de condições instrumentais e sociais que lhe permitam funcionar adequadamente, mantendo a autonomia e a autoestima.

$\mathrm{O}$ fato de as pessoas apresentarem dificuldades ou deficiências na realização de tarefas específicas náo implica na extensão disso para todos os aspectos da vida. Ninguém é deficiente completamente, mas o é em certas situações particulares, frente a tarefas a serem realizadas. O dia a dia é um complexo de situaçóes, açôes e atividades que tornam qualquer indivíduo mais ou menos deficiente, de acordo com a circunstância enfrentada. "A visão interacionista entre fatores constitucionais e ambientais certamente representa a abordagem predominante na atualidade." (OMOTE, 2008, p. 20). Em um estudo de concepçôes sobre as deficiências realizado junto a estudantes de Fisioterapia e Terapia Ocupacional ficou evidente que a visão interacionista era predominante (MAIA; BALEOTTI; OMOTE, 2009).

Contrapondo-se aos modelos já abordados, mas principalmente ao modelo médico, destaca-se o modelo social de deficiência. Nele, a deficiência é resultado da interpretaçáo do meio social. Segundo Omote (1996), no modelo social a deficiência não se caracteriza como algo que emerge com o nascimento de alguém ou com a enfermidade que alguém contrai, mas é produzida e mantida por um grupo social, na medida em que interpreta e trata como desvantagens certas diferenças apresentadas por determinadas pessoas. Em suma, para a conceituação da deficiência, não importa o que causa as limitaçôes ou os impedimentos, mas o que leva alguém a tratar o outro com tais características como sendo deficiente (OMOTE, 1996). A opçấo de eleger uma determinada condiçấo como deficiência depende da relevância que a coletividade, num dado momento histórico, atribui a determinadas competências (OMOTE, 2008). A deficiência é esse fenômeno social e não se identifica com as limitações e/ou impedimentos que uma pessoa pode apresentar em decorrência da posse de uma patologia. Ambos são parte integrante de um mesmo fenômeno.

$\mathrm{O}$ conceito de deficiência vem adquirindo novos sentidos, sendo concebido de forma mais abrangente. $\mathrm{Na}$ análise da deficiência, consideram-se, além das disfunções nas estruturas e funções do corpo, as características relativas aos contextos ambientais - físicos e sociais - que juntos interagem e influenciam a capacidade funcional e a participação social do sujeito.

Essas proposiçóes encontram-se fundamentadas na Classificação Internacional de
Funcionalidade, Incapacidade e Saúde - CIF 2003 (ORGANIZAÇÃO..., 2003). Essa classificação propóe uma nova lógica: rediscutir o conceito de deficiência deslocando o olhar da patologia para os estados de saúde. A CIF busca viabilizar as açóes dos profissionais da saúde em direção a um entendimento do meio como fator que influencia a saúde, bem como à participação ou restrição social do indivíduo. Essa classificação define os componentes da saúde e alguns componentes do bem-estar relacionados com a saúde (tais como educação e trabalho). Comparativamente ao CID 10 - Código Internacional de Doenças, a CIF representa um avanço significativo para a concepção dos profissionais da saúde em relação à deficiência, uma vez que propóe concepções fundamentadas tanto no modelo médico como no modelo social de saúde.

Tendo como parâmetro a integração dos modelos médico e social, busca-se chegar a uma síntese que permita uma visão coerente das diferentes perspectivas de saúde: biológica, individual e social. A CIF não desconsidera limitações que são intrínsecas ao sujeito ao definir a deficiência como "[...] problemas nas funçóes ou estruturas do corpo, tais como um desvio importante ou uma perda [...]" (ORGANIZAÇÃO..., 2003, p. 11), mas também direciona o foco para o meio, destacando o quanto os fatores contextuais podem limitar ou restringir a participação do indivíduo. De acordo com a CIF, os fatores contextuais são as restriçóes causadas por políticas sociais ou barreiras arquitetônicas ou de atitude que aumentam a limitação, negando ou dificultando o acesso a serviços e oportunidades que são inerentes ao homem em sua condição de participação total na sociedade.

Nota-se que nos diferentes momentos históricos, nas diversas organizações sociais e coletividades, foram construídos parâmetros para definir o que é deficiência e, como consequência, produziram-se diferentes concepções e formas de tratamento das pessoas com deficiência. $\mathrm{O}$ entendimento de aspectos históricos relacionados à concepção de deficiência possibilita a compreensão de situaçôes cotidianas frente ao deficiente. A concepção de deficiência pode, em algum grau, influenciar as ações das pessoas frente à pessoa com deficiência.

Nessa perspectiva, as concepçôes sobre deficiência que norteiam teorias e atitudes têm implicaçóes significativas sobre a forma como as pessoas com deficiência são tratadas nas relações cotidianas, bem como sobre a organização e a prestaçáo de serviços a essa população (VIEIRA; DENARI, 2008).

Baleotti (2006) enfatizou que é extremamente importante que a reflexão acerca da concepçáo de 
deficiência bem como acerca das capacidades e limitaçóes e/ou restriçóes impostas pelo contexto social possam estar presentes na formação dos profissionais da saúde, de forma a lhes proporcionar uma visão abrangente do que representa a deficiência. A autora salientou que tal reflexão não deveria constituir-se com base nos referenciais teóricos da área ou nos conceitos de normalidade. Ressaltou ser necessária uma reflexão ancorada em aspectos éticos, socioculturais, políticos e filosóficos, sob uma perspectiva multidimensional, para que se pudessem compreender melhor as açóes destinadas a essa parcela da populaçáo como determinantes da segregação e a partir daí repensar e reestruturar a própria prática profissional no sentido de náo contribuir para a medicalização de alguns problemas primariamente de ordem social.

A reabilitação, a partir das novas conceituaçôes de saúde, doença e deficiência necessita de redefiniçôes. Ao se falar em saúde e reabilitação de pessoas com deficiência é necessário

[...] propor estratégias de ação sobre o universo do ambiente e dos fatores pessoais e náo somente sobre aspectos voltados à patologia e/ou à funcionalidade do indivíduo. (ROCHA, 2006, p. 26).

Torna-se importante a reflexão sobre a concepção que têm acerca da deficiência docentes responsáveis pela formação de profissionais que irão lidar com pessoas com deficiência. A forma como esses docentes concebem a pessoa com deficiência é transmitida aos estudantes em formação. A concepçáo de deficiência se pauta em crenças, valores pessoais e referenciais teóricos da profissão, os quais são transmitidos nas relaçôes que se estabelecem entre docentes e alunos e, futuramente, entre eles e a pessoa com deficiência. Nessa perspectiva, a concepção de deficiência pode determinar a qualidade da relação interpessoal e, consequentemente, a prática profissional destinada a essa população.

Profissionais da Terapia Ocupacional parecem ter valores centrados em uma preocupação holística pelo indivíduo com deficiência. Ao invés de olhar para as limitaçóes e impedimentos, os terapeutas ocupacionais identificam e fortalecem as capacidades e os aspectos saudáveis da pessoa.

A maioria dos terapeutas ocupacionais trabalha com pessoas com diferentes deficiências. Assim, a concepçáo que os docentes de cursos de Terapia Ocupacional têm acerca da deficiência torna-se relevante, pois o papel que desempenham como educadores é um dos elementos decisivos na formação do aluno. A concepção que o professor possui acerca da deficiência conduz o seu fazer pedagógico. Conceber a pessoa com deficiência de maneira diferente da perspectiva médica tradicional, de diagnóstico centrado na doença, na cura e recuperação individual, representa a possibilidade de formar alunos que entendam a deficiência como um problema de dimensôes múltiplas: biológicas, psicológicas, socioculturais, religiosas, ambientais etc., redirecionando o olhar para as diversas influências do mundo externo sobre a deficiência e o seu tratamento.

Dentre os docentes, aqueles que têm formação em Terapia Ocupacional encontram-se em situação privilegiada para formar profissionais com esse perfil por intermédio das atividades de estágio supervisionado. Nelas, os estudantes podem vivenciar problemas e dificuldades concretos de pacientes com as mais variadas patologias, que requerem um olhar integral e multidisciplinar.

Considerando-se o exposto e por entender que

[...] uma visão geral e integradora da pessoa como alguém que interage com seu ambiente orienta a prática da Terapia Ocupacional, ao invés de uma perspectiva de especialização reduzida [...] (YERXA, 2004, p. 494)

objetivou-se neste estudo investigar e analisar a concepção de deficiência na perspectiva de docentes de cursos de Terapia Ocupacional com formaçáo nessa área. A partir disso procurou-se refletir sobre as concepçôes vigentes e sobre a questão da formação de recursos humanos na área.

\section{Material e método}

O presente estudo foi aprovado pelo Comitê de Ética em Pesquisa da Faculdade de Filosofia e Ciências, Unesp, campus de Marília (Parecer n. 958/2010). Os coordenadores dos cursos de Terapia Ocupacional e os docentes participantes concordaram em fazer parte da pesquisa mediante assinatura do Termo de Consentimento Livre e Esclarecido.

Participaram deste estudo 15 docentes com formação em Terapia Ocupacional, sendo sete de duas universidades públicas e oito de duas universidades privadas. Todos os participantes eram do gênero feminino, com idade variando entre 28 e 58 anos. $\mathrm{O}$ tempo de formação na graduação variou de sete a 35 anos. Com relação à titulação, dos 15 participantes, quatro possuíam título de doutor, sendo um em Psicologia Experimental, um em Psicologia da Educação e dois em Educação. Nove participantes possuíam título de mestre, sendo três na área da Psicologia, três em Reabilitação e os outros três em Educação. Dois participantes possuíam título 
de Especialista, um em Terapia da Máo e outro em Dependência Química e Neurologia.

Os dados foram coletados em 2010 por meio de um instrumento denominado Escala de Avaliaçáo da Concepção de Deficiência. Registra-se que essa escala encontra-se em processo de validação e padronização. A versão inicial da escala era composta por 60 itens. Ela foi aplicada a uma amostra de 146 participantes e seus resultados foram utilizados para a análise de itens. A partir dessa análise foram selecionados, para cada concepção, dez itens que melhor mensuram essa concepção. A nova versão da escala, utilizada neste estudo, é composta por 40 itens. Desses, dez foram formulados de modo a expressar a concepção social de deficiência, dez, a concepção médica de deficiência, dez, a concepção embasada em determinantes sociais e outros dez, a concepção interacionista de deficiência. A seguir, explicitam-se exemplos de cada um desses enunciados:

- Concepção social: A deficiência caracteriza-se pela leitura social que se faz dela que, muitas vezes, impede o indivíduo de ter uma participação social igualitária.

- Concepção médica: A deficiência representa a socializaçáo de lesáo ou dano, ou de incapacidade e, como tal, traz consequências ao indivíduo em nível cultural, social, econômico e ambiental.

- Concepção embasada em determinantes sociais: A deficiência é interpretada como decorrente de fatores sociais, emocionais ou outros que podem ocasionar dificuldades para o indivíduo. Fatores esses que possuem explicaçóes externas, ou seja, centradas no ambiente.

- Concepção interacionista: Podemos entender a deficiência como uma condiçáo complexa multideterminada, envolvendo fatores genéticos, fatores ambientais e barreiras atitudinais.

Cada item da escala é constituído de um enunciado seguido de cinco alternativas de resposta: concordo inteiramente, concordo mais ou menos, nem concordo nem discordo, discordo mais ou menos e discordo inteiramente. A terceira alternativa de resposta (nem concordo nem discordo) foi incluída admitindo-se a possibilidade de os participantes não compreenderem o conteúdo do enunciado ou de não terem opinião formada acerca dele. As demais alternativas expressam diferentes graus de concordância ou discordância em relaçáo ao conteúdo do enunciado.

A partir das respostas à escala é calculado um escore para cada concepção de deficiência para cada respondente. Para tanto, inicialmente são atribuídas notas às respostas dadas aos itens. Assim, o assinalamento da alternativa a, que expressa concordância total com o enunciado, recebe a nota 5; o da alternativa b, nota 4, e assim por diante, até o assinalamento da alternativa e, que expressa discordância total e que recebe a nota 1 . Cada participante obtém quatro escores de concepção de deficiência. Esses escores são dados pela soma dos itens que compóem cada concepção; portanto, o escore total de um participante para cada concepção de deficiência pode variar de 10 a 50. A análise estatística foi feita com esses escores.

\section{Resultados e discussão}

Para a compreensão da concepção de deficiência dos docentes de cursos de Terapia Ocupacional foram preliminarmente calculados os valores de variação (indicada pelo escore mínimo e escore máximo), mediana e dispersão (indicada pelos valores de quartil 1 e quartil 3) dos escores relativos a cada uma das quatro concepçóes. Esses valores encontram-se na Tabela 1.

Os parâmetros constantes da Tabela 1 sugerem que a concepção interacionista é a que obteve os maiores escores, seguida das concepções social, médica e da embasada em determinantes sociais. De fato, a comparaçáo dos escores das quatro concepçóes, por meio da prova de Friedman, aponta que há diferença estatisticamente bastante significante entre elas $(p<0,0001)$. A prova de Dunn aponta que há diferenças significantes entre a concepção interacionista e a médica $(\mathrm{p}<0,01)$ e entre aquela e a concepçáo embasada em determinantes sociais ( $\mathrm{p}<0,001)$. Nas demais comparaçôes possíveis, a diferença não chega a ser significante.

Tabela 1. Síntese dos escores das quatro concepções de deficiência.

\begin{tabular}{ccccc}
\hline & $\begin{array}{c}\text { Concepção } \\
\text { interacionista }\end{array}$ & Concepção social & Concepção médica & $\begin{array}{c}\text { Concepção embasada em } \\
\text { determinantes sociais }\end{array}$ \\
\hline Variação & $33-49$ & $28-50$ & $23-43$ & $16-44$ \\
Mediana & 47 & 37 & 35 & 31 \\
Dispersão & $39,5-47$ & $33,5-41,5$ & $31-38,5$ & $21,5-37$ \\
\hline
\end{tabular}


Esses resultados sugerem que os participantes do presente estudo, docentes com graduação em Terapia Ocupacional, não concebem a deficiência como algo que está presente estritamente na pessoa identificada como deficiente. Tanto a concepçáo médica quanto a embasada em determinantes sociais, ainda que os determinantes possam ser ambientais, consideram que a deficiência está localizada no próprio indivíduo. A concepção interacionista, que obteve escores significativamente mais altos que essas duas concepçóes, caracteriza-se pela junção entre fatores constitucionais e ambientais. Pode-se considerar, portanto, que esses docentes têm uma visão integral e holística das deficiências, levando em consideração tanto as limitaçóes impostas pela patologia que o indivíduo possui quanto as limitaçôes ou impedimentos que o seu entorno pode impor mediante restriçáo de oportunidades. Tal visão constitui elemento determinante para o planejamento de intervenções em busca da solução de problemas apresentados por pessoas com deficiência mas cujo foco de atenção não seja apenas a pessoa mas também o meio.

Um estudo realizado por Almeida e Trevisan (2010) demonstra formas de ações terapêuticas ocupacionais aparentemente embasadas em concepção interacionista da deficiência. As autoras salientam que na atenção à Saúde Mental as práticas terapêuticas ocupacionais se preocupam com o desenvolvimento de açóes náo mais num setting terapêutico fechado mas nos contextos reais de vida do paciente e na inserção em atividades do cotidiano que lhe sejam significativas, garantindo assim a sua participação ativa no processo terapêutico.

Mesmo os estudantes de Terapia Ocupacional, que se encontram em processo de formação profissional e ainda náo tiveram oportunidade de vivenciar a experiência de atendimento a pessoas com deficiência, parecem possuir uma perspectiva integral e holística de deficiência. No estudo realizado por Maia, Baleotti e Omote (2009), os estudantes de Terapia Ocupacional demonstraram concordar mais com as concepçóes interacionista e social do que com a concepção médica e a embasada em determinantes sociais. Entre esses estudantes, a concepção social recebeu os maiores escores, seguida das concepçóes interacionista, médica e embasada em determinantes sociais. Os autores encontraram diferenças estatisticamente significantes na comparação tanto da concepçáo social quanto da concepção interacionista com a concepção médica e a concepçấo embasada em determinantes sociais. Entre a concepçáo social e a interacionista, como também entre a concepção médica e a embasada em determinantes sociais não foram encontradas diferenças estatisticamente significantes.

A diferença mais importante que se encontra entre os resultados do presente estudo e os de Maia, Baleotti e Omote (2009) diz respeito às concepçôes social e interacionista. Entre os docentes, a concepção mais valorizada é a interacionista e, entre os estudantes, é a social. Embora em nenhum dos estudos a diferença entre essas duas concepçóes fosse estatisticamente significante, pode-se aventar a hipótese de que, para os estudantes que ainda não têm a vivência da prática clínica talvez possa parecer mais adequada a ideia de que a deficiência seja, em grande medida, decorrência das restrições impostas pelo meio social. Já para os docentes a experiência profissional pode revelar que as dificuldades, limitaçôes ou impedimentos que pessoas com deficiência apresentam podem também ser resultado da presença de alguma patologia.

$\mathrm{Na}$ realidade, ninguém parece ter um modo de ver a deficiência que se enquadre rigorosamente em uma das quatro concepções tratadas no presente estudo. Mesmo as pessoas que compreendem a deficiência como decorrência de algum problema orgânico presente no corpo da pessoa identificada como deficiente parecem admitir a possibilidade de a imposição das limitaçóes e impedimentos pelo meio social constituir-se como um dos determinantes da deficiência. A propósito da causalidade, é bastante comum a ideia de que a deficiência é multideterminada, incluindo-se aí desde fatores genéticos até condições sociais a que a criança está exposta desde a mais tenra idade.

Nessa perspectiva, pode ser interessante identificar a coocorrência de diferentes concepçōes, o que pode sugerir um perfil complexo de concepção mantido por participantes deste estudo. A Tabela 2 apresenta os coeficientes de correlação entre as concepções e o respectivo nível de significância.

A concepção interacionista apresenta correlação significante em relaçáo à concepção social $\left(r_{s}=0,60\right.$; $\mathrm{p}<0,02)$ e à concepção médica $\left(\mathrm{r}_{\mathrm{s}}=0,65 ; \mathrm{p}<0,01\right)$, mas não em relação à concepção embasada em determinantes sociais $\left(r_{s}=0,37 ; p>0,05\right)$. A concepção

Tabela 2. Correlações entre as concepções.

\begin{tabular}{ccc}
\hline Concepções & $\begin{array}{c}\text { Coeficiente de } \\
\text { correlação }\end{array}$ & $\begin{array}{c}\text { Nível de } \\
\text { significância }\end{array}$ \\
\hline $\mathrm{CI} \times \mathrm{CS}$ & 0,60 & $\mathrm{p}<0,02$ \\
$\mathrm{CI} \times \mathrm{CM}$ & 0,65 & $\mathrm{p}<0,01$ \\
$\mathrm{CI} \times \mathrm{CDS}$ & 0,37 & $\mathrm{p}>0,05$ \\
$\mathrm{CS} \times \mathrm{CM}$ & 0,45 & $\mathrm{p}>0,05$ \\
$\mathrm{CS} \times \mathrm{CDS}$ & 0,71 & $\mathrm{p}<0,01$ \\
$\mathrm{CM} \times \mathrm{CDS}$ & 0,02 & $\mathrm{p}>0,05$ \\
\hline
\end{tabular}


social, por sua vez, mantém correlação significante com a concepção embasada em determinantes sociais $\left(r_{s}=0,01 ; p<0,01\right)$, mas não com a concepção médica $\left(r_{s}=0,45 ; p>0,05\right)$. Por fim, entre a concepção médica e a embasada em determinantes sociais, a correlação é virtualmente nula $\left(r_{s}=0,02 ; p>0,05\right)$. Significa que a concepçáo interacionista coocorre com as concepçóes social e médica, mas não com a concepção embasada em determinantes sociais; a concepção social coocorre com a concepção embasada em determinantes sociais, mas não com a concepção médica; e é notável a quase independência total entre a concepção médica e a embasada em determinantes sociais, com o coeficiente de correlação praticamente igual a zero.

O conjunto dos resultados apresentados nas Tabelas 1 e 2 indica que as quatro concepçóes são endossadas pelos participantes deste estudo, dos escores mais altos para os mais baixos, na seguinte ordem: concepção interacionista, concepção social, concepção médica e concepção embasada em determinantes sociais. Nessa sequência, entre a concepção interacionista e a social não há diferença significante, mas entre aquela e a concepção médica $(\mathrm{p}<0,01)$ e a embasada em determinantes sociais $(\mathrm{p}<0,001)$ há diferenças estatisticamente significantes. Já os escores da concepção social não são significantemente superiores aos das concepçóes médica e da embasada em determinantes sociais, ocorrendo o mesmo entre essas duas últimas concepçôes.

Uma vez que essas concepções náo parecem mutuamente exclusivas, sugerindo haver alguma complementaridade, pode-se sugerir a possibilidade de que os participantes endossem tanto a concepção na qual dá-se destaque, a título de deficiência, às limitaçôes e impedimentos que a pessoa deficiente apresenta quanto a concepção na qual pelo menos parte da condição de deficiência é atribuída à leitura que o meio social faz dessas limitaçôes e impedimentos. As concepçóes médica e embasada em determinantes sociais tipicamente dão foco ao indivíduo que é tratado como deficiente e as concepçóes interacionista e social dáo foco ao entorno dessa pessoa tratada como deficiente.

Assim, pode-se aventar a hipótese de que as pessoas tendem a apresentar ao mesmo tempo a concepçáo interacionista e a médica ou a concepção social e a embasada em determinantes sociais. A amostra muito pequena deste estudo não permite uma análise mais detalhada para verificar essa hipótese. Estudos futuros nessa direçáo podem ser relevantes para uma melhor compreensão da postura assumida por profissionais da área ou docentes a partir de suas concepçóes acerca das deficiências.

\section{Conclusões}

A concepção dos docentes universitários graduados em Terapia Ocupacional parece trazer em seu bojo conceitos tanto de caráter interacionista e social quanto, talvez complementarmente, de caráter médico e do embasado em determinantes sociais. Como professores de cursos de Terapia Ocupacional, o seu modo de conceber as deficiências pode ter importantes repercussōes na formação dos futuros profissionais dessa área, permitindo-lhes desenvolver uma abordagem holística dos problemas de seus pacientes.

O grupo de professores deste estudo parece não estar alheio ao papel que desempenham na formação dos alunos do curso de Terapia Ocupacional. Parece estar consciente da possibilidade concreta de contribuir para que o aluno avance no pensamento abstrato e reflita sobre a pessoa com deficiência e sobre o seu entorno social, sobretudo sobre as condições atitudinais e sociais, que podem contribuir tanto para a construção de um ambiente inclusivo, com um clima acolhedor e solidário, quanto para a exclusão, constituindo-se como barreiras para o acesso às mais variadas oportunidades.

Este estudo traz implicaçóes relevantes para a área da Terapia Ocupacional no sentido de contribuir para a elucidação da compreensão que os docentes têm acerca da deficiência. A partir dessa compreensão é possível refletir sobre as concepçóes atuais e discutir a questão da formação dos alunos. Dada a importância das questóes tratadas e a necessidade de se buscarem evidências claras e fecundas para a verificaçáo da hipótese levantada, sugere-se a continuidade da investigação mediante a ampliaçáo do número de participantes, bem como a introdução no estudo de profissionais com formação em outras áreas, a fim de se verificar a eventual tendência que se observa atualmente em relaçáo ao fenômeno da deficiência.

\section{Referências}

ALMEIDA, D. T.; TREVISAN, E. R. Estratégias de intervenção da Terapia Ocupacional em consonância com as transformações da assistência em saúde mental no Brasil. Interface: Comunicação, Saúde, Educação, Botucatu, v. 14 , p. 187-195, 2010. http://dx.doi.org/10.1590/ S1414-32832010005000030

BALEOTTI, L. R. Um estudo do ambiente educacional inclusivo: descrição das atitudes sociais em relação à inclusão e das relaçóes interpessoais. 2006. 183 f. Tese (Doutorado em Educação)-Faculdade de Filosofia e 
Ciências, Universidade Estadual Paulista, Marília, 2006. PMid:16756606.

BALEOTTI, L. R.; DEL MASSO, M. C. S. Diversidade, diferença e deficiência no contexto educacional. In: OLIVEIRA, A. A. S. et al. (Org.). Inclusão Escolar: as contribuições da Educação Especial. São Paulo: Cultura Acadêmica Editora; Marília: Fundepe Editora, 2008. p. 33-44.

BRASIL. Secretaria de Educação Especial. Projeto Escola Viva-Garantindo o acesso e permanência de todos os alunos na escola-Alunos com necessidades educacionais especiais. Brasília: MEC/SEESP, 2000. v. 1.

MAIA, J. C.; BALEOTTI, L. B.; OMOTE, S. Concepções de deficiência na perspectiva de estudantes de Fisioterapia e de Terapia Ocupacional. In: CONGRESSO BRASILEIRO MULTIDISCIPLINAR DE EDUCAÇÃO ESPECIAL, 5., 2009, Londrina. Anais... Londrina: UEL, 2009.

MORI, L.; OLIVEIRA. F. I. W. Concepção dos professores de uma Escola Municipal de Ensino Fundamental I sobre sua formação e atuação frente ao processo de inclusão de alunos com deficiência. In: CONGRESSO BRASILEIRO DE EDUCAÇÃO ESPECIAL, 7.; ENCONTRO NACIONAL DOS PESQUISADORES DA EDUCAÇÃO ESPECIAL, 5., 2012, São Carlos. Anais... São Carlos: Editora Cubo, 2012. p. 3399-3413.

OMOTE, S. Deficiência e não-deficiência: recortes do mesmo tecido. Revista Brasileira de Educação Especial, Piracicaba, v. 2, p. 65-73, 1994.

OMOTE, S. Perspectivas para conceituação de deficiências. Revista Brasileira de Educação Especial, Piracicaba, v. 4, n. 1, p. 127-135, 1996.

OMOTE, S. Diversidade, educação e sociedade inclusiva. In: OLIVEIRA, A. A. S. et al. (Orgs.). Inclusão Escolar: as contribuições da Educação Especial. São Paulo:
Cultura Acadêmica Editora; Marília: Fundepe Editora, 2008. p. 15-32.

ORGANIZAÇÃO MUNDIAL DA SAÚDE - OMS. CIF - Classificação Internacional de Funcionalidade, Incapacidade e Saúde. OMS, 2003.

OTHERO, M. B.; DALMASO, A. S. W. Pessoas com deficiência na atenção primária: discurso e prática de profissionais em um centro de saúde-escola. Interface: Comunicação, Saúde, Educação, Botucatu, v. 13, n. 28, p. 177-188, 2009. http://dx.doi.org/10.1590/ S1414-32832009000100015

PAN, M. A. S.G. O direito à diferença: uma reflexão sobre deficiência intelectual e educação inclusiva. Curitiba: IBPEX, 2008.

RESENDE, M. C.; NERI, A. L. Atitudes de adultos com deficiência física frente ao idoso, à velhice pessoal e a pessoas com deficiência física. Estudos de Psicologia, Campinas, v. 22, p. 123-131, 2005. http://dx.doi.org/10.1590/ S0103-166X2005000200002

ROCHA, E. F. Deficiência e Reabilitação: Questôes Históricas e Epistemológicas. In: ROCHA, E. F. (Org.). Reabilitação de pessoas com deficiência: a intervenção em discussão. São Paulo: Roca, 2006. p. 9-60.

TELFORD, C. W.; SAWREY, J. M. O Individuo Excepcional. 5. ed. Rio de janeiro: Guanabara, 1988.

VIEIRA, C. M.; DENARI, F. E. Concepções infantis sobre a deficiência mental: efeitos de um programa informativo. In: ALMEIDA, M. A. et al. (Org.). Temas em Educação Especial: deficiências sensoriais e deficiência mental. São Carlos: UFScar, 2008. p. 289-297

YERXA, E. J. Experiência Social e Psicológica de Ser Portador de Deficiência: Implicaçóes para os Terapeutas Ocupacionais. In: PEDRETTI, L. W.; EARLY, M. B. Terapia Ocupacional: Capacidades práticas para a disfunção física. São Paulo: Roca, 2004. p. 493-517.

\section{Contribuição dos Autores}

Os autores trabalharam juntos em todas as etapas de produçáo do texto.

\section{Notas}

1 Este artigo faz parte de pesquisa científica aprovado pelo Comitê de Ética em Pesquisa em Seres Humanos da Faculdade de Filosofia e Ciências, Unesp, Marília, Parecer no 958/2010. 